\title{
Urinary neutrophil gelatinase-associated lipocalin as graft dysfunction predictor at one year of kidney transplantation
}

Lina María Serna-Higuita, ${ }^{1,2}$ John Fredy Nieto-Ríos, ${ }^{2}$ Catalina Ocampo-Kohn, ${ }^{2}$ Arbey Aristizabal-Alzate, ${ }^{2}$ Gustavo Adolfo Zuluaga-Valencia² and Fabián Jaimes-Barragán ${ }^{3}$

${ }^{1}$ Tübingen University Hospital, Department of Epidemiology and Biometrics, Tübingen, Germany; ${ }^{2}$ Universidad de Antioquia, Hospital Pablo Tobón Uribe, Department of Nephrology and Kidney Transplantation; ${ }^{3}$ Universidad de Antioquia, Hospital Pablo Tobón Uribe, Department of Research, Medellín, Colombia

\begin{abstract}
Introduction: Recent studies suggest that urinary neutrophil gelatinase-associated lipocalin (UNGAL) is superior to creatinine for renal graft dysfunction early detection, but there are only few studies assessing its usefulness as long-term predictor of said function. Objective: To explore if UNGAL values within the first 48 hours after kidney transplantation predict graft function on the long term. Method: Prospective cohort, where uNGAL values were assessed at 2, 12, 24 and 48 hours post-kidney transplantation. Results: Seventy-nine kidney transplant recipients were evaluated. At one year of follow-up, $30.4 \%$ of patients had graft dysfunction. No statistically significant differences were found between the UNGAL values and the renal graft function at one year $(p=0.65)$; the multivariate analysis showed that no UNGAL value was a predictor marker of graft dysfunction at one year of kidney transplantation. Conclusion: The UNGAL values obtained within the first 48 hours post-transplant were not associated with graft dysfunction at one year of kidney transplantation.
\end{abstract}

KEY WORDS: Lipocalin. Graft loss. Kidney transplantation.

\section{Introduction}

Delayed graft function (DGF), defined as the need for renal replacement therapy during the first 7 days post-transplant or serum creatinine not decreasing $<10 \%$ for 3 consecutive days, ${ }^{1}$ is one of the most common complications of kidney transplantation; ${ }^{2}$ it originates due to the ischemia-reperfusion injury that occurs after kidney transplantation and has been shown to be a risk factor for acute rejection and renal graft acute nephropathy that may favor its loss within the first year. ${ }^{3-6}$ Different therapeutic approaches to prevent DGF have been explored; however, successful options in animal models have not been reproduced in humans ${ }^{3,7}$ owing to late identification of this injury, ${ }^{3,8-10}$ since current biomarkers for its diagnosis (which include serum creatinine and urinary output) are poorly sensitive for its prediction..$^{11-14}$

There is a current need for more sensitive and specific markers that enable DGF and subclinical kidney injury early diagnosis, ${ }^{15}$ in order for therapeutic interventions that increase renal graft survival to be established..$^{3,16}$ Recent studies suggest that urinary neutrophil gelatinase-associated lipocalin (UNGAL) could be superior to serum creatinine for DGF early detection, since its elevation can occur within the first 12 hours after kidney transplantation in patients with subclinical dysfunction. ${ }^{3,5,7,16-26}$ However, there are only few studies that have assessed UNGAL usefulness as a long-term predictor of renal graft function, and it is not clear whether its values can predict dysfunction. 2,18,21,27,28

At Hospital Pablo Tobón Uribe, in Antioquía, Medellin, Colombia, deceased donor transplants, where the
Correspondence:

Lina María Serna-Higuita

E-mail: Im.serna@ hotmail.com
Date of reception: 25-11-2016

Date of acceptance: 05-06-2017

DOI://dx.doi.org/10.24875/GMM.M18000142
Gac Med Mex. 2018;154:221-227

Contents available at PubMed www.gacetamedicademexico.com 
prevalence of DGF is higher, are predominant, and a higher prevalence of subclinical kidney injury is therefore to be expected. We consider that UNGAL might be a good prognostic marker to predict renal function at one year of kidney transplantation. In one study previously conducted by our group, UNGAL value 48 hours post-kidney transplantation was found to be a DGF early predictor; however, it turned was not a better predictor when compared with serum creatinine. ${ }^{29}$

In this article, we describe the results of a cohort of patients followed for one year with the purpose to explore whether UNGAL values within the first 48 hours after kidney transplantation predict long-term graft function. ${ }^{18}$

\section{Method}

This was a prospective cohort-type study. The cohort was initially established in order to assess the relationship of UNGAL values obtained at 1, 12, 24 and 48 hours from kidney transplantation and the presence or not of DGF. ${ }^{29}$ Subsequently, for the performance of this second study, the cohort follow-up was continued for a one-year period after the kidney transplantation.

This study was carried out at the Pablo Tobón Uribe Hospital. Patients older than 12 years diagnosed with end-stage chronic kidney disease (CKD) who received a kidney transplantation between November 2012 and December 2013 were included. Patients with anuria within the first hour after kidney transplantation were excluded. Induction treatment used in this cohort consisted of basiliximab $20 \mathrm{mg}$ on days 0 and 4 in low immune risk patients or $1 \mathrm{mg} / \mathrm{kg} /$ day of thymoglobulin for 3 to 5 days in patients with high immune risk and 3 methylprednisolone boluses. Maintenance treatment consisted of a triple immunosuppression regimen with prednisolone, an antiproliferative agent (mycophenolate or azathioprine) and a calcineurin inhibitor (tacrolimus or cyclosporine). All patients were followed-up during the year following the kidney transplantation by nephrologists blinded to the UNGAL values.

Primary outcome measure was defined as a glomerular filtration rate (GFR) $<60 \mathrm{~mL} /$ minute $/ 1.74 \mathrm{~m}^{2}$ body surface area (BSA) as estimated with the CKD-EPI equation $^{30}$ during the first year after the kidney transplantation. Serum creatinine values for the above estimate were measured during patient monthly follow-up during the first year post-kidney transplantation. As exposure variable, UNGAL values obtained at 1, 12, 24 and 48 hours post-kidney transplantation were used. Other assessed clinical parameters included gender, age, chronic kidney disease (CKD) etiology, history of kidney transplantation and dialysis prior to transplant, cold and warm ischemia time, immunosuppressant treatment and presence of DGF; the latter was defined by the need for dialysis in the first week post-kidney transplantation or serum creatinine decrease $<10 \%$ for 3 consecutive days or a serum creatinine value $>3 \mathrm{mg} / \mathrm{dL}$ at day 5 post-kidney transplantation.

\section{Data source, laboratory procedures}

$10 \mathrm{~mL}$ of urine were collected from each patient directly from the bag attached to the urinary catheter that was permanent during the first post-transplantation days; urine that was previously contained in the bag was previously discarded in order to collect fresh urine. Samples were taken at 1, 12, 24 and 48 hours post-transplant and sent to the hospital laboratory in less than 1 hour from collection, where they were centrifuged at $400 \mathrm{rev}$ olutions per minute and stored at $-70{ }^{\circ} \mathrm{C}$ until they were processed. UNGAL determination was performed by means of turbidimetric immunoassay, from the Sentinel Diagnostics manufacturer (REF 1P9300), on Abbott's Architect ${ }^{\circledR}$ i8000 platform. The samples were processed within a period of $<3$ months since the take. Serum creatinine was routinely measured by enzymatic method, daily during the first week post-transplant, and monthly thereafter over the following 12 months.

\section{Sample size and power}

A time-to-event model was used, with UNGAL values within the first 48 post-transplant hours being regarded as the exposure variable and GFR $<60 \mathrm{~mL} /$ minute $/ 1.73 \mathrm{~m}^{2} \mathrm{BSA}$ in the first post-transplant year as the outcome variable of interest. ${ }^{31}$

Given that a cohort with a defined sample size (79 patients) was analyzed, the power to detect the risk ratio (RR) for graft dysfunction was estimated according to the UNGAL values in the first 48 hours post-transplant. The assumptions used were: RR of 2;29,32,33 expected proportion of transplanted patients with graft dysfunction: $35 \% .^{10,22}$ According to the above assumptions, and with an alpha error of 0.05 , this cohort had a power of 0.881 to identify a RR of 2 with a GFR $<60 \mathrm{~mL} /$ minute $/ 1.73 \mathrm{~m}^{2} \mathrm{BSA}$ during the first year post-transplantation in patients with elevated uNGAL values.

The patients were grouped according to the primary outcome measure: presence or not of graft dysfunction at one year of kidney transplantation; whether the 
UNGAL values predicted renal graft dysfunction was explored in both groups.

\section{Statistical analysis}

Descriptive statistics was used, and the distribution of variables was verified by means of the Kolmogorov-Smirnov test. Quantitative variables were expressed as means and standard deviation or medians and interquartile ranges, according to data distribution; qualitative variables were analyzed as proportions. Dispersion diagrams were plotted between the $\mathrm{UN}$ GAL values of thew first 48 hours and GFR by CKDEPI one year post-kidney transplantation; subsequently, the correlation between both these variables was assessed using Pearson's correlation coefficient ( $r$ ).

The discriminatory capacity of the different UNGAL values for the detection of renal graft dysfunction during the first year following transplantation was explored and a Kaplan-Meier survival analysis was carried out. A Cox proportional risks model was also constructed.

\section{Ethical aspects}

This study was approved by the Pablo Tobón Uribe Hospital ethics and research committee, and the regulations on ethical aspects of research in human subjects contained in resolution 008430 , issued by the Ministry of Health of Colombia in 1993, were followed; in addition, the confidentiality of included patients' personal data was preserved. On the other hand, this study did not pose any risks for patients, since blood tests were part of the kidney transplantation protocol and the UNGAL samples were directly obtained from the collection bag attached to the permanent urinary catheter patients had after kidney transplantation.

\section{Results}

Between November 2012 and December 2013, 83 kidney transplantations were carried out at Pablo Tobón Uribe Hospital; 2 patients were excluded owing to anuria in the first hours and 2 because they were younger than 12 years, with 79 patients being left. One patient died during follow-up; however, his GFR was normal at the moment of death, and he was therefore included in the group of patients. All patients received deceased donor kidney transplantation, but none included any of the extended criteria (donor $>60$ years of age or between 50 and 60 years of age with at least two of the following criteria: history of high blood pressure, serum creatinine levels $>1.5 \mathrm{mg} / \mathrm{mL}$ or with stroke as cause of death). Most patients ( $n=44,55.7 \%$ ) were males, mean age was $39.6 \pm 4.18$ years; for $91.1 \%(n=72)$ it was their first transplantation, and $82.3 \%(n=65)$ were on dialysis prior to the transplantation, with a median of 23.5 months (interquartile range $[\mathrm{IQR}]=4-48$ ). Previous transfusions had been received by $51.9 \%(n=41)$, and cold ischemia time had a mean of $15.04 \pm 5.84$ hours. DGF occurred in 13 patients (16.5\%), with 5 of them $(6.3 \%)$ requiring dialysis during the first week. At one-year follow-up, 24 patients (30.4\%) had renal graft dysfunction; demographic characteristics, grouped by presence or not of renal graft dysfunction are shown in Table 1.

No correlation was found between 1 year post-transplant GFR by CKD-EPI and UNGAL values at 1, 12, 24 and 48 hours $(r=0.14, p=0.2 ; r=0.05, p=0.66$; $r=0.06, p=0.61 ; r=0.11, p=0.34$, respectively); neither was another pattern of behavior observed (Fig. 1).

Figure 2 shows the ROC curves and their respective areas under the curve for each UNGAL value at 1,12 , 24 and 48 hours post-transplant with regard to renal graft dysfunction outcome at one year $(0.569$ [95\% $\mathrm{Cl}=0.424-0.715], 0.542[95 \% \mathrm{Cl}=0.406-0.678], 0.55$ $[95 \% \mathrm{Cl}=0.398-0.702]$ and $0.55[95 \% \mathrm{Cl}=0.408$ 0.692], respectively).

\section{uNGAL values behavior}

Seventy-five percent $(n=59)$ of patients had an uNGAL drop higher than $50 \%$ in the first 48 hours, $15 \%$ ( $n=12)$ had a $\leq 50 \%$ decrease, and in 8 patients (10 \%) UNGAL values were increased with regard to the first measurement. The percentage of patients free of renal graft dysfunction at 6 and 12 months post-transplant according to UNGAL levels behavior was 88 and $71 \%$ in the group with > $50 \%$ drop; 74 and $65 \%$ in the group with $<50 \%$ decrease, and 62 and $62 \%$, respectively, in the group where UNGAL values were increased (Fig. 3) (log-rank test $p=0.65$ ).

The Cox proportional risk model according to UNGAL behavior 48 hours post-transplant showed no statistically significant association with renal graft dysfunction occurrence one year after transplantation (Table 2).

Among the patients with graft dysfunction $(n=24)$, $16.7 \%(n=4)$ had previously developed DGF, in comparison with $16.4 \%(9 / 54)$ in patients with GFR > $60 \mathrm{~mL} /$ minute $/ 1.73 \mathrm{~m}^{2}$ BSA ( $\left.p=0.6\right)$.

\section{Discussion}

In this cohort of 79 patients with kidney transplantation, all from deceased donors, UNGAL values in the 
Gaceta Médica de México. 2018;154

Table 1. Descriptive analysis grouped by renal graft dysfunction outcome during the first year post-transplant

\begin{tabular}{|c|c|c|c|c|}
\hline \multirow[t]{2}{*}{ Variable } & \multicolumn{2}{|c|}{ GFR $\leq 60 \mathrm{~mL} /$ minute $(\mathrm{n}=24)$} & \multicolumn{2}{|c|}{ GFR $>60 \mathrm{~mL} /$ minute $(n=55)$} \\
\hline & $\mathrm{n}$ & $\%$ & $\mathrm{n}$ & $\infty \%$ \\
\hline Male gender & 8 & 33.3 & 36 & 65 \\
\hline History of previous transfusions & 19 & 79.2 & 46 & 83 \\
\hline Second transplantation & 0 & 0 & 7 & $\frac{-12}{4}$ \\
\hline Previous dialysis & 19 & 79.2 & 46 & 83 \\
\hline Induction with basiliximab & 5 & 20.8 & 20 & 36 \\
\hline Induction with thyroglobilin & 19 & 79.2 & 35 & -63 \\
\hline Delayed renal draft function & 4 & 16.7 & 9 & $\frac{5}{3} 16$ \\
\hline $\begin{array}{l}\text { Need for dialysis in the first week after kidney } \\
\text { transplantation }\end{array}$ & 1 & 4.2 & 4 & 7 \\
\hline \multirow[t]{2}{*}{ Acute rejection in the first year following transplantation } & 10 & 41.7 & 6 & $\subset 10$ \\
\hline & \multicolumn{2}{|c|}{ Mean \pm SD } & \multicolumn{2}{|c|}{ Mean \pm SD } \\
\hline Age at transplantation (years) & \multicolumn{2}{|c|}{$40.67 \pm 15.07$} & \multicolumn{2}{|c|}{$39.07(13.88)$} \\
\hline Donor's age (years) & \multicolumn{2}{|c|}{$35.67 \pm 15.78$} & \multicolumn{2}{|c|}{$27 \pm 11.28$} \\
\hline Donor's creatinine (mg/dL) & \multicolumn{2}{|c|}{$0.98 \pm 0.34$} & \multicolumn{2}{|c|}{$0.84 \pm 0.27$} \\
\hline Cold ischemia time (hours) & \multicolumn{2}{|c|}{$14.54 \pm 6.08$} & \multicolumn{2}{|c|}{$15.13 \pm 5.80$} \\
\hline Warm ischemia time (hours) & \multicolumn{2}{|c|}{$33.75 \pm 7.11$} & \multicolumn{2}{|c|}{$32.81 \pm 7.51$} \\
\hline DR incompatibility & \multicolumn{2}{|c|}{$1.5 \pm 0.5$} & \multicolumn{2}{|c|}{$1.2 \pm 0.6$} \\
\hline HLA total incompatibility & \multicolumn{2}{|c|}{$4.9 \pm 0.8$} & \multicolumn{2}{|c|}{$4.2 \pm 1$} \\
\hline \multicolumn{5}{|l|}{ Post-kidney transplantation GFR (mL/minute/1.73 m² BSA) } \\
\hline At 5 days & \multicolumn{2}{|c|}{$56.93 \pm 26.62$} & \multicolumn{2}{|c|}{$58.59 \pm 32.52$} \\
\hline \multirow[t]{2}{*}{ At 6 months } & \multicolumn{2}{|c|}{$53.37 \pm 24.25$} & \multicolumn{2}{|c|}{$68.22 \pm 19.56$} \\
\hline & \multicolumn{2}{|c|}{ Median (IQR) } & \multicolumn{2}{|c|}{ Median (IQR) } \\
\hline \multicolumn{3}{|l|}{ Post-kidney transplantation creatinine (mg/dL) } & & $\frac{\mathrm{c}}{\mathrm{c}}$ \\
\hline Day 1 & & & & \\
\hline Day 2 & & & & \\
\hline Day 3 & & & & 59) \\
\hline Day 4 & & & & \\
\hline Day 5 & & & & 68) \\
\hline Day 30 & & & & 52) \\
\hline Post-kidney transplantation uNGAL (ng/mL) & & & & בـ \\
\hline At 1 hour $(n=79)$ & & & & 03) \\
\hline At 12 hours $(n=78)^{*}$ & & & & 86.9) \\
\hline At 24 hours $(n=78)^{\star}$ & & & & $6.3)$ \\
\hline At 48 hours $(n=77)$ & & & & \\
\hline
\end{tabular}

GFR=glomerular filtration rate, IQR=interquartile range.

${ }^{*}$ One female patient had thrombosis and renal graft loss at first hour of transplantation and only taking the first UNGAL sample was possible.

first 48 post-transplant hours were not shown to be predictors of graft insufficient function at 12 months of follow-up. Neither was a correlation found between UNGAL values and GFR at one year of kidney transplantation or could a cutoff point be established for UNGAL that was able to discriminate patients with graft dysfunction.
Currently, there is no biomarker that enables early predicting renal graft long-term result. UNGAL has been proposed as a useful biomarker for DGF early detection; ${ }^{19,28,34-36}$ however only few studies have assessed its role as a long-term biomarker of renal graft dysfunction. ${ }^{37}$ We considered useful to explore whether UNGAL values in kidney transplantation recipients 

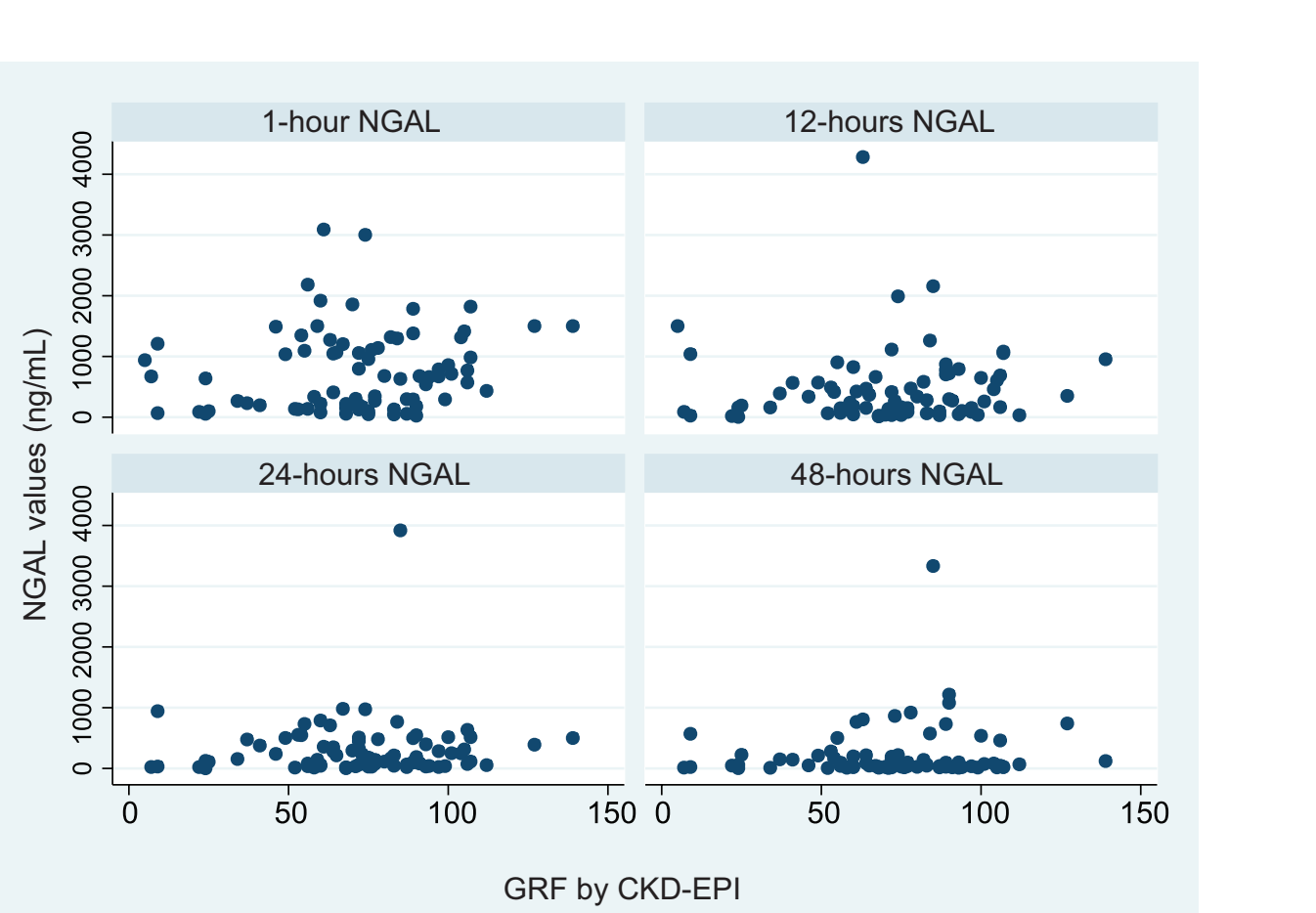

Figure 1. UNGAL values dispersion plots in the first 48 hours post-transplant and glomerular filtration rate values estimated by the CKD-EPI formula at 1 year of kidney transplantation.

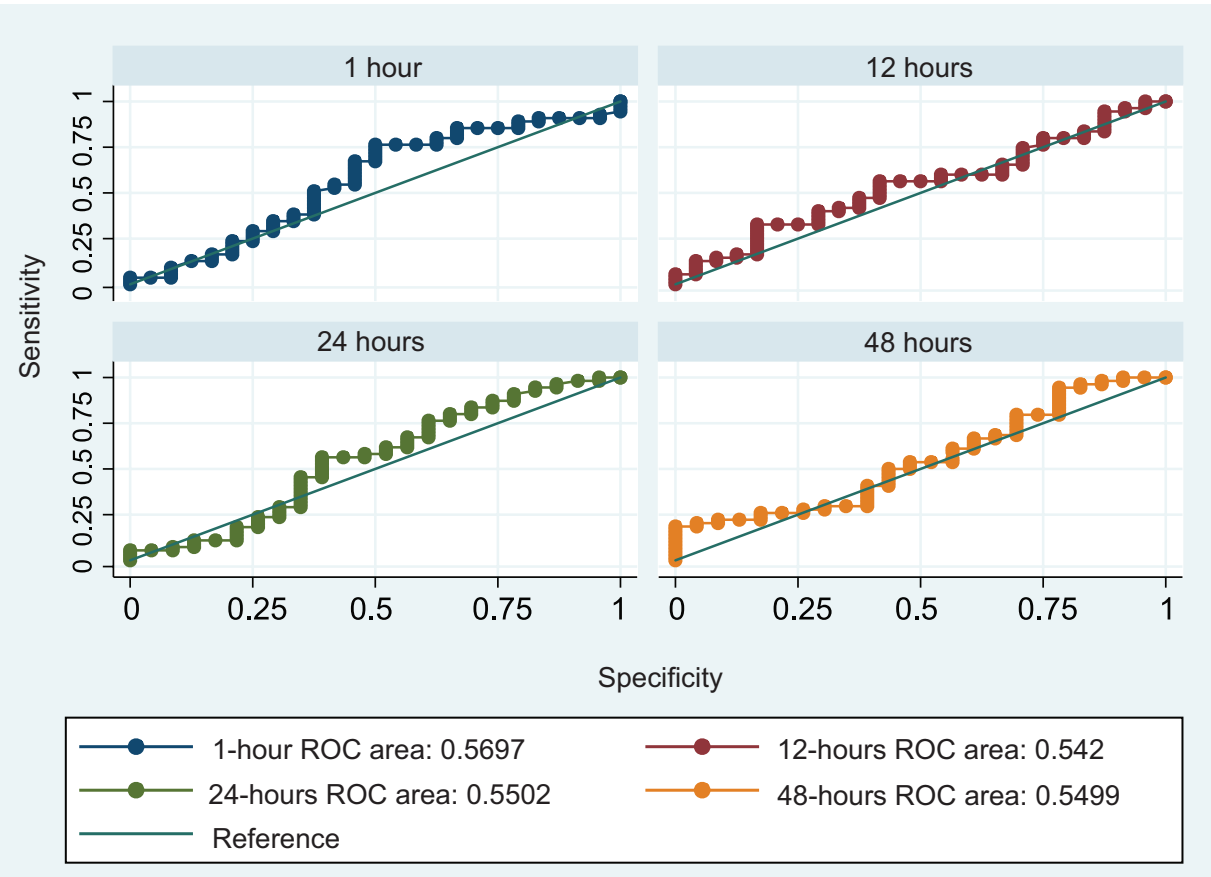

Figure 2. UNGAL first 48-hour values ROC curves.

with no evidence of DGF can predict long-term renal graft dysfunction; this might suggest that subclinical renal injury not diagnosed by serum creatinine values but rather by uNGAL elevated levels might have an impact on long-term renal graft function, regardless of the presence or not od DGF and would enable treatment strategies to be established in order to prevent or limit renal damage before it becomes irreversible. ${ }^{5}$

Different studies have suggested that UNGAL values measured within the first 48 hours after kidney 
Table 2. Cox proportional risk model to predict renal graft dysfunction at 1-year post-transplant according to uNGAL behavior

\begin{tabular}{lccc}
\hline & RR & 95\% Cl & p \\
\hline uNGAL $^{*}$ decrease $>50$ & 1 & Reference & \\
uNGAL $^{*}$ decrease $<50$ & 1.412 & $0.474-4.205$ & 0.535 \\
uNGAL* increase & 1.59 & $0.466-5.439$ & 0.459 \\
\hline
\end{tabular}

*During the first 48 hours after kidney transplantation.

$\mathrm{RR}=$ risk ratio, $\mathrm{Cl}=$ confidence interval.

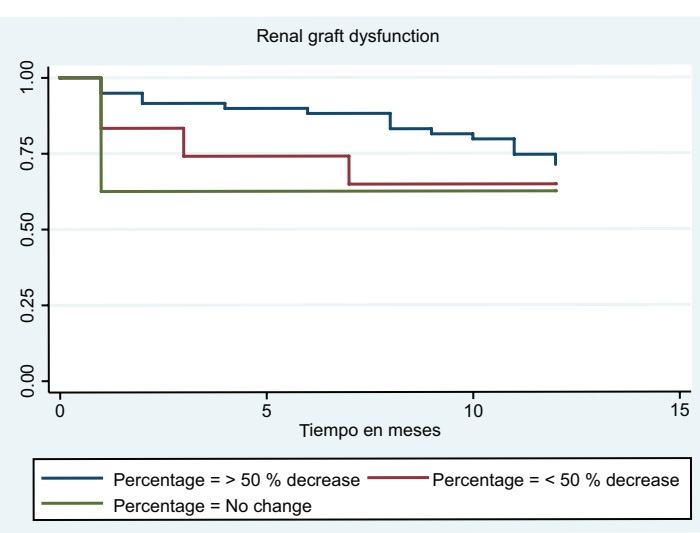

Figure 3. Kaplan-Meier curve for graft survival estimation according to uNGAL behavior in the first 48 hours.

transplantation predict long-term renal graft function. Hall et al. measured the uNGAL values at 0, 6, 12, 18, 24 and 48 hours post-deceased donor kidney transplantation in 92 patients. The patients with UNGAL values higher than percentile 66 had higher serum creatinine levels 3 months after kidney transplantation ( $p$ $=0.004) .{ }^{3}$ The same group carried out another study in 153 patients with kidney transplantation who had 24 renal graft losses and 13 dysfunctions during the 1-year follow-up. When UNGAL values were compared according to the presence or not of renal graft dysfunction, UNGAL values were higher in patients with this outcome in comparison with those without it ( $\mathrm{UN}$ GAL $911 \mathrm{ng} / \mathrm{mL}$ [percentiles 25-75 = 133-3143], in contrast with $370 \mathrm{ng} / \mathrm{mL}$ [percentiles 25-75 $=29-2381$ ], respectively $[p=0.002])$. In the logistic regression analysis, UNGAL values measured on day 1 after kidney transplantation were significantly associated with renal graft poor function $(\mathrm{OR}=6 ; 95 \% \mathrm{Cl}=1.5-24) .{ }^{27}$ Choi et al., in a study carried out in 69 patients with kidney transplantation, found that UNGAL values were significantly higher in those patients with renal graft dysfunction one year after kidney transplantation; furthermore, in the multivariate logistic regression analysis, UNGAL values at post-transplantation day 2 were independent predictors of poor graft function $(\mathrm{OR}=$ 1.003; $95 \% \mathrm{Cl}=1.001-1.005) ; 18$ however, after two years' follow-up, day 0, 2 and 6 post-kidney transplantation UNGAL values were not significantly associated with poor graft function. ${ }^{28}$

Fonseca et al. assessed 42 patients; in the linear regression analysis they found that UNGAL values at day 7 post-transplant adjusted for a history of acute rejection and re-hospitalization were independently associated with serum creatinine values (regression coefficient $=0.138$; $95 \% \mathrm{Cl}=0.041-0.235) .{ }^{21}$ Conversely, Rahizamdeh et al. observed that UNGAL values measured at days 1, 3 and 7 post-kidney transplantation were not associated with kidney dysfunction one year after transplantation, ${ }_{2}^{2}$ which are similar findings to those in our study.

One possible explanation for the differences between the results of previous studies and ours is the type of outcome measure assessed. Hall et al. used a GFR < $30 \mathrm{~mL} / \mathrm{min} / 1.73 \mathrm{~m}^{2} \mathrm{BSA}$ at one year of transplantation to define graft dysfunction, ${ }^{3}$ Fonseca et al. used serum creatinine values at one year of kidney transplantation as outcome measure. Another important difference is the type of population. The presence of donors with extended criteria ( $>60$ years of age, or between 50 and 60 years of age with at least two of the following criteria: high blood pressure, creatinine levels $>1.5 \mathrm{mg} / \mathrm{dL}$ or stroke as cause of death) is associated with higher risk for renal graft loss. ${ }^{38}$ This is explained because renal response to the ischemia-reperfusion injury after kidney transplantation is a balance between repair and fibrosis processes: in the presence of severe injury, progressive fibrosis and renal graft scarring takes place; in mild cases or in the presence of suitable quality grafts, renal epithelial cell recovery is achieved without importantly affecting the graft function.

In out cohort, there were no extended criteria donors; all of them were young and had no associated comorbidities or kidney dysfunction during the process of death (donor serum creatinine prior to extraction: $0.9 \pm 0.4 \mathrm{mg} / \mathrm{dL}$ ), which might explain the lower frequency of subclinical injury or the successful recovery of renal grafts from ischemia-reperfusion injury. In contrast, the percentage of donors with extended criteria in Hall and Choi studies was 18 and $30.9 \%,{ }^{3,18}$ respectively. In addition, donors' age in the different studies ranged from 42 to 51 years, ${ }^{3,18,21,27}$ whereas mean age of our population's donors was $29.6 \pm 14.18$ years.

Among the limitations of our study, the sample size and the low proportion of patients with the outcome of interest stand out, which suggests that there was no sufficient power to find statistically significant differences and to estimate the effect of potential confounding variables such as cold ischemia time, the induction 
therapy used and patient adherence to the treatment protocols, which may influence on kidney function on the short and long term.

\section{Conclusion}

In our cohort of patients with kidney transplantation from donors that met optimal criteria, UNGAL values in the first post-transplant hours were not associated with long-term graft dysfunction. Further investigations are required in order to identify the true role played by UNGAL values in long-term graft function, taking into account other populations at risk for DGF and kidney dysfunction.

\section{Acknowledgements}

To Abbot and Novartis Laboratories for the donation of kits to process the UNGAL.

\section{Conflicts of interest}

We declare that none of the authors has any conflicts of interest.

\section{References}

1. Cohen DJ, Vella JoV. Transplantation. NephSAP. 2011;10(6).

2. Rahimzadeh N, Otukesh H, Hoseini R, Sorkhi H, Otukesh M, Hoseini S, et al. Are serum and urine neutrophil gelatinase-associated lipocalin predictive of renal graft function in short term? Pediatr Transplant. 2012;16(7):796-802

3. Hall IE, Yarlagadda SG, Coca SG, Wang Z, Doshi M, Devarajan P, et al. $\mathrm{IL}-18$ and urinary NGAL predict dialysis and graft recovery after kidney transplantation. J Am Soc Nephrol. 2010;21(1):189-197.

4. Alvarez S, Suazo C, Boltansky A, Ursu M, Carvajal D, Innocenti G, et al. Urinary exosomes as a source of kidney dysfunction biomarker in rena transplantation. Transplant Proc. 2013:45(10):3719-3723.

5. Bataille A, Abbas S, Semoun O, Bourgeois E, Marie O, Bonnet F, et al. Plasma neutrophil gelatinase-associated lipocalin in kidney transplantation and early renal function prediction. Transplantation. 2011;92(9): 1024-1030.

6. Kono H, Nakagawa K, Morita S, Shinoda K, Mizuno R, Kikuchi E, et al. Effect of a novel nuclear factor- $\square B$ activation inhibitor on renal ischemia-reperfusion injury. Transplantation. 2013;96(10):863-870.

7. Parikh CR, Jani A, Mishra J, Ma Q, Kelly C, Barasch J, et al. Urine NGAL and IL-18 are predictive biomarkers for delayed graft function following kidney transplantation. Am J Transplant. 2006;6(7):1639-1645.

8. Haase M, Bellomo R, Devarajan P, Schlattmann P, Haase-Fielitz A, NGAL Meta-analysis Investigator Group. Accuracy of neutrophil gelatinase-associated lipocalin (NGAL) in diagnosis and prognosis in acute kidney injury: a systematic review and meta-analysis. Am J Kidney Dis. 2009;54(6):1012-1024.

9. Lin M, Li L, Pokhrel G, Qi G, Rong R, et al. The protective effect of baicalin against renal ischemia-reperfusion injury through inhibition of inflammation and apoptosis. BMC Complement Altern Med. 2014;14(1):19.

10. Perico N, Cattaneo D, Sayegh M, Remuzzi G. Delayed graft function in kidney transplantation. Lancet. 2004;364:1814-1827.

11. Yarlagadda SG, Coca SG, Garg AX, Doshi M, Poggio E, Marcus RJ, et al. Marked variation in the definition and diagnosis of delayed graft function: a systematic review. Nephrol Dial Transplant. 2008;23(9):2995-3003.

12. Devarajan P. NGAL in acute kidney injury: from Serendipity to utility. Am J Kidney Dis. 2008;52(3):395-399.

13. Adiyanti SS, Loho T. Acute kidney injury (AKI) biomarker. Acta Med Indones. 2012;44(3):246-255.

14. Hall IE, Doshi MD, Poggio ED, Parikh CR. A comparison of alternative serum biomarkers with creatinine for predicting allograft function after kidney transplantation. Transplantation. 2011;91(1):48-56.
15. Heyne N, Kemmner S, Schneider C, Nadalin S, Königsrainer A, Häring HU. Urinary neutrophil gelatinase-associated lipocalin accurately detects acute allograft rejection among other causes of acute kidney injury in renal allograft recipients. Transplantation. 2012;93(12):1252-1257.

16. Lee EY, Kim MS, Park Y, Kim HS. Serum neutrophil gelatinase-associated lipocalin and interleukin-18 as predictive biomarkers for delayed graft function after kidney transplantation. J Clin Lab Anal. 2012;26(4):295-301.

17. Bolignano D, Donato V, Coppolino G, Campo S, Buerni A, Lacquaniti A, et al. Neutrophil gelatinase-associated lipocalin (NGAL) as a marker of kidney damage. Am J Kidney Dis. 2008;52(3):595-605.

18. Choi HM, Park KT, Lee JW, Cho E, Jo SK, Cho WY, et al. Urine neutrophil gelatinase-associated lipocalin predicts graft outcome up to 1 year after kidney transplantation. Transplant Proc. 2013;45(1):122-128.

19. Rostami Z, Nikpoor M, Einollahi B. Urinary neutrophil gelatinase associated lipocalin (NGAL) for early diagnosis of acute kidney injury in renal transplant recipients. Nephrourol Mon. 2013;5(2):745-752.

20. Kanter J, Beltran S, Molina D, Vallecillo J, Sancho A, Gavela E, et al. Urinary neutrophil gelatinase-associated lipocalin after kidney transplantation: is it a good biomarker to assess delayed graft function? Transplant Proc. 2013;45(4):1368-1370.

21. Fonseca I, Oliveira JC, Almeida M, Cruz M, Malho A, Martins LS, et al. Neutrophil gelatinase-associated lipocalin in kidney transplantation is an early marker of graft dysfunction and is associated with one-year renal function. J Transplant. 2013;2013:650123.

22. Hollmen ME, Kyllönen LE, Inkinen KA, Lalla MLT, Salmela KT. Urine neutrophil gelatinase-associated lipocalin is a marker of graft recovery after kidney transplantation. Kidney Int. 2011;79(1):89-98.

23. Lebkowska U, Malyszko J, Lebkowska A, Koc-Zorawska E, Lebkowski W, Malyszko JS, et al. Neutrophil gelatinase-associated lipocalin and cystatin C could predict renal outcome in patients undergoing kidney allograft transplantation: a prospective study. Transplant Proc. 2009;41(1):154-157.

24. Kaufeld JK, Gwinner W, Scheffner I, Haller HG, Schiffer M. Urinary NGAL ratio is not a sensitive biomarker for monitoring acute tubular injury in kidney transplant patients: NGAL and ATI in renal transplant patients. J Transplant. 2012;2012:563404.

25. Vanmassenhove J, Vanholder R, Nagler E, Van-Biesen W. Urinary and serum biomarkers for the diagnosis of acute kidney injury : an in-depth review of the literature. Nephrol Dial Transplant. 2013;28(10):254-273.

26. Field M, Lowe D, Cobbold M, Higgins R, Briggs D, Inston N, et al. The use of NGAL and IP-10 in the prediction of early acute rejection in highly sensitized patients following HLA-incompatible renal transplantation. Transpl Int. 2014;27(4):362-370.

27. Hall IE, Doshi MD, Reese PP, Marcus RJ, Thiessen-Phitbrook $H$, Parikh CR. Association between peritransplant kidney injury biomarkers and 1-year allograft outcomes. Clin J Am Soc Nephrol, 2012;7(8): 1224-1233.

28. Yang J, Choi HM, Seo MY, Lee JY, Kim K, Jun H, et al. Urine liver-type fatty acid-binding protein predicts graft outcome up to 2 years after kidney transplantation. Transplant Proc. 2014;46(2):376-380.

29. Nieto-Ríos JF, Serna-Higuita LM, Ocampo C, Aristizabal A, Vélez C Vanegas JJ, et al. NGAL como predictor temprano de función retardada del injerto renal. Biomedica. 2016;36(2):213-219.

30. Shaffi K, Uhlig K, Perrone RD, Ruthazer R, Rule A, Lieske JC, et al. Performance of creatinine-based GFR estimating equations in solid-organ transplant recipients. Am J Kidney Dis. 2014;63(6):1007-1018.

31. Díaz P, Fernández P. Cálculo del tamaño muestral para la determinación de factores pronósticos. Cad Aten Primaria. 2002;9:30-33.

32. Halloran PF, Aprile MA, Farewell V, Ludwin D, Smith EK, Tsai SY, et al. Early function as the principal correlate of graft survival. A multivariate analysis of 200 cadaveric renal transplants treated with a protocol incorporating antilymphocyte globulin and cyclosporine. Transplantation. 1988;46.(2):223-228.

33. Johnston O, O'kelly P, Spencer S, Donohoe J, Walshe JJ, Little DM, et al. Reduced graft function (with or without dialysis) vs immediate graft function: a comparison of long-term renal allograft survival. Nephrol Dial Transpl. 2006;21(8):2270-2274.

34. Yarlagadda SG, Coca SG, Formica RN, Poggio ED, Parikh CR. Association between delayed graft function and allograft and patient survival: a systematic review and meta-analysis. Nephrol Dial Transplant. 2009; 24(3):1039-1047.

35. Ponticelli C. Ischaemia-reperfusion injury: a major protagonist in kidney transplantation. Nephrol Dial Transplant. 201429(6):1134-1140.

36. Mishra J, Ma Q, Kelly C, Mitsnefes M, Mori K, Barasch J, et al. Kidney NGAL is a novel early marker of acute injury following transplantation. Pediatr Nephrol. 2006;21(6):856-863.

37. Ramirez-Sandoval JC, Herrington W, Morales-Buenrostro LE. Neutrophil gelatinase-associated lipocalin in kidney transplantation: a review. Transplant Rev. 2016;29(3):139-144.

38. Melilli E, Bestard O, Cruzado JM, Zorita IN, Grinyó JM, Castelao AM Trasplante de riñones con criterios expandidos : manejo y resultados a largo plazo. Nefrologia. 2011;2(5):98-104 